Original Article

\title{
Assessment of obsessive-compulsive disorder comorbidity and obsessive-compulsive symptom dimensions in patients with schizophrenia
}

\author{
Abmet Kokurcan, MD, Yasir Şafak, MD.
}

\begin{abstract}

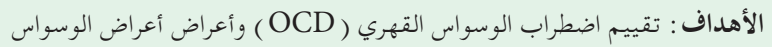
القهري ( OCS ) في المرضى الذين يعانواب الون من مرض انفصام الشخصية.

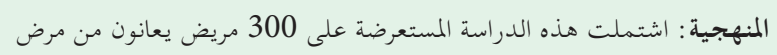

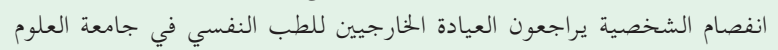

الصحية الفصام الشخصية

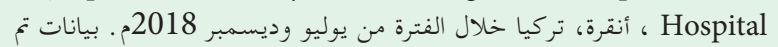

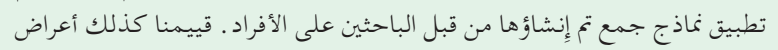

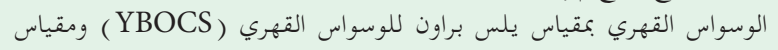

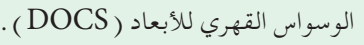

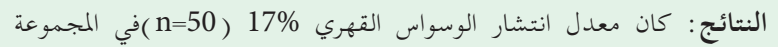

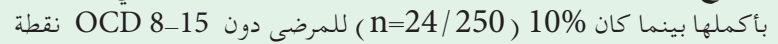
في YBOCS. كشف اختبار ANOVA أحادي الاتجاه أن المرضى الذين

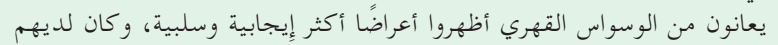

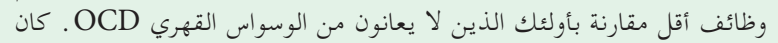

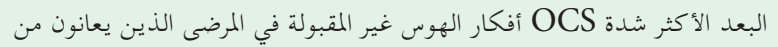

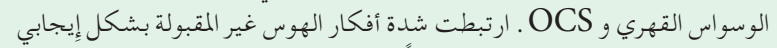

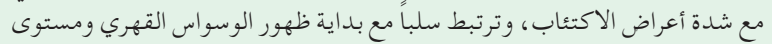
البصيرة في تحليل الارتباط بيرسون وترني

الحخلاصة : يجب تقييم المرضى الذين يعانون من مرض انفصام الشخصية لوجود

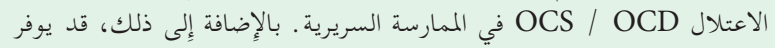

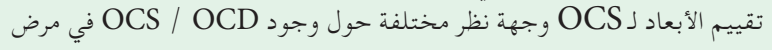
انفصام الشخصية.

Objectives: To assess obsessive-compulsive disorder (OCD) comorbidity and obsessive-compulsive symptom (OCS) dimensions in patients with schizophrenia.

Methods: This cross-sectional study included 300 patients with schizophrenia who were applied to the to the Outpatient PsychiatryClinic of Health Sciences University Dışkapı Yıldırım Beyazıt Training and Research Hospital, Ankara, Turkey between July and December 2018. Data collection forms created by researchers were applied to the individuals. Obsessive-compulsive symptom were assessed with the Yale-Brown Obsessive Compulsive Scale (YBOCS) and the Dimensional Obsessive Compulsive Scale (DOCS).

Results: The OCD prevalence was $17 \%(\mathrm{n}=50)$ in the whole group while $10 \%(n=24 / 250)$ of the patients without OCD had 8-15 points at YBOCS. One-way ANOVA test revealed that the patients with OCD showed more severe positive, negative, and depressive symptoms, and also had lower functionality compared to those without OCD $(p<0.05)$. The most severe OCS dimension was unacceptable obsessional thoughts in the patients with OCD and OCS. The severity of unacceptable obsessional thoughts was positively correlated with the depressive symptom severity, and negatively correlated with onset age of OCD and insight level in Pearson correlation analysis.

Conclusion: Patients with schizophrenia should be evaluated for presence of the OCS/OCD comorbidity in clinical practice. In addition, dimensional assessment of OCS might provide a different viewpoint on the presence of OCS/OCD in schizophrenia.

Keywords: schizophrenia, comorbidity, obsessive behavior

Saudi Med J 2020; Vol. 41 (3): 275-282 doi: $10.15537 /$ smj.2020.3.24909

From the Department of Psychiatry, Faculty of Medicine, Health Sciences University, Dışkapı Yıldırım Beyazıt Training and Research Hospital, Ankara, Turkey.

Received 29th August 2019. Accepted Gth January 2020.

Address correspondence and reprint request to: Dr. Ahmet Kokurcan, Department of Psychiatry, Faculty of Medicine, Health Sciences University, Dışkapı Yıldırım Beyazı Training and Research Hospital, Ankara, Turkey. E-mail: ahmetkokurcan@gmail.com

ORCID ID: https://orcid.org/0000-0002-5763-2506 
P atients with schizophrenia manifest dissimilar clinical features and show a varied clinical course. ${ }^{1}$ Characteristics of schizophrenia are categorized as core psychotic features, cognitive symptoms, and other clinical features. ${ }^{2}$ Mood episodes and obsessive-compulsive symptoms (OCS) are considered as distinct dimensions in clinical manifestation of schizophrenia. ${ }^{3}$ Obsessivecompulsive symptoms and psychotic features show a high coexistence in patients with schizophrenia and OCS might arise at any stage of schizophrenia. While some patients presenting OCS meet the diagnostic criteria for obsessive-compulsive disorder (OCD) comorbidity, others do not encounter the OCD criteria. ${ }^{4}$ Concurrent presence of OCD and schizophrenia was approximately $10 \%$ and OCS rate in patients with schizophrenia was determined higher in previous studies. ${ }^{5-7}$ Distinct type of obsessions and compulsions in clinical manifestation may basically highlight the same symptom dimension. ${ }^{8}$ In addition, a wide variety of clinical characteristics can be demonstration of an obsession and/or compulsion in patients with schizophrenia. ' Clinical expression of psychotic symptoms also reveal a great variability between the individuals with schizophrenia. ${ }^{10}$ Therefore, the relationship between OCS and psychotic features in schizophrenia have not been clearly understood yet. ${ }^{11}$ There is a paucity of research on the dimensional assessment of OCS in schizophrenia. ${ }^{12}$ Additionally, the studies inquiring the relationship between OCS and psychotic features did not exhibit consistent results. ${ }^{13-17}$ There was a significant association between the OCD comorbidity and the severity of psychotic features in some studies, whereas others did not determine a significant relationship between those characteristics. ${ }^{13-17}$ Most of the studies suggested a poor cognitive performance in the patients with OCS/OCD comorbidity, while others did not determine a significant relationship between the OCS/OCD presence and cognitive abilities. ${ }^{17,18}$ In a recent study, severe OCS was associated with a poor functionality in the patients with schizophrenia, although those manifesting mild OCS showed a higher functionality. ${ }^{16}$ Consequently, OCS/OCD presence in schizophrenia still lacks a clear definition in the current literature. $^{19}$

There are some aspects of the relationship between OCS and features of schizophrenia, primarily that impact of the OCS/OCD comorbidity on schizophrenia differs

Disclosure. Authors have no conflict of interests, and the work was not supported or funded by any drug company. depending on the onset of OCS/OCD. ${ }^{19,20}$ Different dimensions of OCS is considered as another important aspect of the issue; however, most of the studies applied the dichotomy of obsessions/compulsions at inquiring the relationship between OCS/OCD comorbidity and schizophrenia characteristics. ${ }^{19,21}$ Consequently, there is not enough evidence on the OCS dimensions in patients with schizophrenia. ${ }^{19,21}$ The studies evaluating the kind of obsession and compulsions in schizophrenia are relatively older and obtained inconsistent results. While some studies reported a high rate of repetitive behaviors in patients with schizophrenia and OCD comorbidity, others revealed that checking and arranging compulsions were more common. ${ }^{22,23}$ Furthermore, majority of those studies utilized the Yale-Brown Obsessive Compulsive Symptoms Scale (YBOCS) in the assessment of OCS/ OCD features in schizophrenia. ${ }^{24}$ However, YBOCS measures the severity of OCS, nevertheless, it does not highlight a dimensional profile of the symptoms. As OCS exhibit a varied clinical appearance, dimensional approach can provide a better clarification on the impact of OCS/OCD comorbidity on schizophrenia. ${ }^{25}$ Taken that background, we aimed to assess OCD comorbidity and OCS dimensions in patients with schizophrenia, and to investigate the relationship between different OCS dimensions and schizophrenia features.

Methods. Patients with schizophrenia according to DSM-5 criteria who were applied to the Outpatient Psychiatry Clinic of Health Sciences University Dışkapı Yıldırım Beyazıt Training and Research Hospital, Ankara, Turkey between July and December 2018 were assessed for the study. Patients age between 18 and 60 years with a schizophrenia diagnosis for at least 6 months were included in the study. ${ }^{26}$ The sample of the study was limited to Ankara, the capital city of Turkey, and 300 patients got involved. Patients with organic brain disorders $(n=16)$, neurodevelopmental disorders $(n=8)$, and alcohol or substance use disorders $(n=12)$ were excluded, and also those who did not understand the items or did not succeed to finish all scales were not included. Written informed consent was obtained from all participants and the study was conducted in accordance with the ethical principles of the Declaration of Helsinki. Ethical approval for the study was granted by the Ethical Commission of the Health Sciences University (Ankara, Turkey, No: 2018/48/16).

Theparticipantswereadministered byBriefPsychiatric Rating Scale (BPRS), Clinical Global Impressions Scale-Severity (CGI-S), Scale for the Assessment of Positive and Negative Symptoms (SAPS/SANS), Calgary Depression Scale for Schizophrenia (CDSS), 
YBOCS, The Dimensional Obsessive Compulsive Scale (DOCS), and Global Assessment of Functioning Scale (GAF). ${ }^{24,27,32}$ The interviewer was a psychiatrist (AK) who has a good experience for the administration of the scales in patients with schizophrenia. The BPRS assesses different psychiatric symptoms such as anxiety, depression and indicates an overview on the severity of clinical features. ${ }^{27}$ The CGI-S demonstrates severity of the disorder through clinician assessment and its score is ranged between 1-7. ${ }^{28}$ The SAPS/SANS scales are frequently applied in clinical practice to evaluate severity of positive and negative symptoms. ${ }^{29}$ The SAPS exhibits positive symptom severity such as delusions, disorganized behaviors, whereas negative symptoms like alogia, avolition are evaluated with the SANS. ${ }^{29}$ The CDSS is applied to distinguish negative and depressive symptoms in schizophrenia. ${ }^{30}$ The YBOCS is one of the most common scales in measuring the severity of OCS. ${ }^{24}$ Both obsession and compulsion parts of the scale have 5 items and are scored between 0 and $20 .{ }^{24}$ The DOCS is a 20 -item scale and figures out an integrative evaluation of obsessive-compulsive features. ${ }^{31}$ The DOCS scale is categorized in 4 dimensions: as contamination, responsibility, unacceptable obsessional thoughts, and symmetry/completeness. The GAF is assigned with a clinical decision of functioning level between 0 to 100 in patients with schizophrenia. ${ }^{32}$ Prior studies related with that study were determined through inquiring free search engines such as PubMed, Scopus, and so forth.

Statistical analysis. The scales defined above were administered to the subjects and statistical analyses were conducted using the Statistical Package for Social Sciences (SPSS) version 21 (Armonk, NY: IBM Corp.). To compare the variables between the patients with and without OCD, independent samples t-test, Chi-square test of independence, and one-way ANOVA tests were used for normally distributed data while Mann Whitney-U and Kruskal Wallis $\mathrm{H}$ tests were used for the data not conforming to a normal distribution. Bonferroni test was used for post-hoc comparison of the patients with sub-threshold OCS, OCD, and without OCD. In addition, Pearson correlation analysis was applied to evaluate the association between the DOCS subscales and the clinical characteristics in patients with OCD comorbidity. All $p$-values were calculated as 2 -sided, and $p$-values less than 0.05 were considered statistically significant.

Results. That study consisted of 300 patients with schizophrenia and $70 \%$ of the patients $(n=210)$ were male, $71 \%$ was not married $(n=214), 34 \%$ was graduated from high school $(\mathrm{n}=102)$. Obsessive- compulsive disorder comorbidity was diagnosed by common decision of 2 psychiatrists (AK, YŞ) according to DSM-5 criteria in the assessment of the individuals. The OCD prevalence was $17 \%(\mathrm{n}=50)$ in the whole group while 250 patients (83\%) did not have an OCD diagnosis for a life-time. Also, $10 \%(n=24)$ of the patients without OCD had a YBOCS score of 8 to 15 , and $90 \%(n=226)$ showed a YBOCS score of 8 or lower. Comparison of the patients with OCD, without OCD, and with sub-threshold OCS did not show a significant difference in terms of sociodemographic characteristics $(p>0.05)$.

The mean duration of schizophrenia was $15.03 \pm 8.18$ years and it did not show a significant difference between 3 groups $(p=0.601)$. However, there was a significant difference in comparison of all other clinical features between the 3 groups $(p<0.05)$. Onset of the disorder was younger in those with OCD, and subthreshold OCS comparing with those without OCD $\left(21.30 \pm 4.70,21.04 \pm 4.44,24.52 \pm 7.53, x^{2}=12.460\right.$, $p=0.002)$. One-way ANOVA test revealed that the patients with OCD showed higher SANS $(p=0.005)$, SAPS $(p=0.003)$, CGI $(p=0.001)$, BPRS $(p=0.001)$, CDSS $(p=0.033)$, and lower GAF $(p=0.001)$ scores compared to the patients without OCD. Furthermore, total YBOCS score, YBOCS obsession and compulsion scores were positively correlated with the CGI-S, BPRS, SANS, SAPS, and CDSS scores in patients with OCD comorbidity $(p<0.05)$. However, in patients without OCD, no statistically significant difference was determined between the severity of clinical symptoms and all YBOCS scores $(p>0.05)$. Post-hoc analysis revealed that the SANS, CDSS, and CGI-S scores did not show a statistically significant difference between the patients with OCD, and those with sub-threshold OCS (SANS: $33.18 \pm 7.53,31.04 \pm 6.81, p=0.903$; CDSS: $2.74 \pm 2.13,2.46 \pm 1.50, p=1.000$; CGI-S: $4.10 \pm 0.65$, $3.88 \pm 0.68, p=0.624)$. In addition, the SAPS, BPRS, and GAF scores were not statistically different in the patients without OCS, and those with sub-threshold OCS $(p>0.05)$. The individuals with sub-threshold OCS had higher SANS $(p=0.748)$, CDSS $(p=0.782)$, and SAI $(p=1.000)$ scores in comparison with those without OCD, nevertheless, the difference was not statistically significant. Comparison of the clinical characteristics between the 3 groups is presented in Table 1, and post-hoc comparison is demonstrated in Table 2.

The mean YBOCS score was $20.60 \pm 4.07$ in patients with OCD, and 10.58 \pm 2.06 with sub-threshold OCS $(p<0.001)$. The dimension of "unacceptable obsessional thoughts" was the most severe OCS dimension in both 
Table 1 - Comparison of the sociodemographic and clinical characteristics between the patients with OCD, without OCD, and those with sub-threshold OCS.

\begin{tabular}{|c|c|c|c|c|c|}
\hline Sociodemographic & $\begin{array}{c}\text { Patients with } \\
\text { OCD } \\
(\mathrm{n}=50)\end{array}$ & $\begin{array}{c}\text { Patients without } \\
\text { OCD } \\
(\mathrm{n}=226)\end{array}$ & $\begin{array}{l}\text { Patients with sub- } \\
\text { threshold OCS } \\
(\mathbf{n}=24)\end{array}$ & $P$-value & $\mathrm{F}=2.367$ \\
\hline $\mathrm{Age}^{\mathrm{a}}$ & $36.96 \pm 9.88$ & $39.66 \pm 1.17$ & $35.83 \pm 7.72$ & 0.096 & \\
\hline $\begin{array}{l}\text { Gender }^{b} \\
\text { Female } \\
\text { Male }\end{array}$ & $\begin{array}{l}15(30) \\
35(70)\end{array}$ & $\begin{array}{c}67(30) \\
159(70)\end{array}$ & $\begin{array}{c}8(33) \\
16(67)\end{array}$ & 0.932 & $x^{2}=0.140$ \\
\hline $\begin{array}{l}\text { Marital status } \\
\text { Single or seperated } \\
\text { Married }\end{array}$ & $\begin{array}{l}34(68) \\
16(32)\end{array}$ & $\begin{array}{c}158(70) \\
68(30)\end{array}$ & $\begin{array}{c}22(92) \\
2(8)\end{array}$ & 0.532 & $x^{2}=0.390$ \\
\hline $\begin{array}{l}\text { Education level } \\
\text { Primary school or lower } \\
\text { Middle school } \\
\text { High school } \\
\text { University }\end{array}$ & $\begin{array}{c}14(28) \\
15(30) \\
14(28) \\
7(14)\end{array}$ & $\begin{array}{l}64(28) \\
59(26) \\
80(35) \\
23(10)\end{array}$ & $\begin{array}{l}6(25) \\
7(29) \\
8(33) \\
3(13)\end{array}$ & 0.951 & $x^{2}=1.620$ \\
\hline Onset age of schizophrenia ${ }^{c}$ & $21.30 \pm 4.70$ & $24.52 \pm 7.53$ & $21.04 \pm 4.44$ & $0.009^{*}$ & $\mathrm{~F}=6.829$ \\
\hline Duration of schizophrenia ${ }^{a}$ & $15.08 \pm 8.72$ & $15.19 \pm 8.32$ & $13.42 \pm 7.22$ & 0.601 & $\mathrm{~F}=0.509$ \\
\hline Number of hospitalizations $s^{c}$ & $3.72 \pm 2.86$ & $2.95 \pm 1.82$ & $3.46 \pm 1.74$ & 0.063 & $x^{2}=3.753$ \\
\hline SANS $^{a}$ & $33.18 \pm 7.53$ & $28.98 \pm 8.60$ & $31.04 \pm 6.81$ & $0,005^{*}$ & $F=5.494$ \\
\hline SAPS ${ }^{a}$ & $33.38 \pm 8.37$ & $28.73 \pm 9.14$ & $28.25 \pm 7.10$ & $0.003^{*}$ & $F=5.868$ \\
\hline $\mathrm{BPRS}^{\mathrm{a}}$ & $25.80 \pm 8.57$ & $20.69 \pm 9.01$ & $20.63 \pm 5.93$ & $0.001^{*}$ & $F=7.150$ \\
\hline $\mathrm{CGI}^{\mathrm{a}}$ & $4.10 \pm 0.65$ & $3.69 \pm 0.74$ & $3.88 \pm 0.68$ & $0.001^{*}$ & $F=6.770$ \\
\hline $\mathrm{GAF}^{\mathrm{a}}$ & $51.90 \pm 8.51$ & $57.01 \pm 9.08$ & $57.08 \pm 6.58$ & $0.001^{*}$ & $F=7.023$ \\
\hline $\mathrm{CDSS}^{\mathrm{a}}$ & $2.74 \pm 2.13$ & $2.00 \pm 1.88$ & $2.46 \pm 1.50$ & $0.033^{*}$ & $F=3.448$ \\
\hline $\mathrm{SAI}^{\mathrm{a}}$ & $9.6 \pm 1.96$ & $10.35 \pm 2.18$ & $10.54 \pm 2.19$ & 0.084 & $\mathrm{~F}=2.501$ \\
\hline \multicolumn{6}{|c|}{$\begin{array}{c}\text { Data are mean } \pm \text { standard deviation, or number percentage (\%). }{ }^{a} \text { One-way ANOVA test, }{ }^{b} \text { Chi-square test of independence, }{ }^{c} \text { Kruskal } \\
\text { Wallis } \mathrm{H} \text { test, }{ }^{*} p<0.05 \text {, OCD: obsessive-compulsive disorder, OCS: obsessive compulsive symptoms, BPRS: brief psychiatric rating } \\
\text { scale, CGI: Clinical Global Impressions Scale, SAPS/SANS: Scale for the Assessment of Positive and Negative Symptoms, } \\
\text { GAF: Global Assessment of Functioning Scale, CDSS: Calgary Depression Scale for Schizophrenia, SAI: schedule for assessing the } 3 \\
\text { components of insight }\end{array}$} \\
\hline
\end{tabular}

Table 2 - Post-hoc Bonferroni test comparing clinical characteristics of the patients with OCD, without OCD, and those with subthreshold OCS.

\begin{tabular}{|c|c|c|c|c|c|c|c|}
\hline \multicolumn{2}{|c|}{ Comparison between groups } & \multirow{3}{*}{$\begin{array}{c}\text { Variable } \\
\text { SANS }\end{array}$} & \multirow{3}{*}{$\begin{array}{c}\begin{array}{c}\text { Mean } \\
\text { Difference (I-J) }\end{array} \\
4.198 \\
2.138\end{array}$} & \multirow{3}{*}{$\begin{array}{l}\text { S.E. } \\
1.299 \\
2.063\end{array}$} & \multirow{3}{*}{$\begin{array}{c}\text { Significance } \\
0.004^{*} \\
0.903\end{array}$} & \multicolumn{2}{|c|}{$95 \% \mathrm{CI}$} \\
\hline & & & & & & \multirow{2}{*}{$\begin{array}{c}\text { Lower } \\
1.07 \\
-2.83\end{array}$} & \multirow{2}{*}{$\begin{array}{c}\text { Upper } \\
7.32 \\
7.11\end{array}$} \\
\hline Patients with OCD & $\begin{array}{l}\text { Patients without OCD } \\
\text { Patients with OCS }\end{array}$ & & & & & & \\
\hline Patients with OCS & Patients without OCD & SANS & 2.059 & 1.784 & 0.748 & -2.24 & 6.35 \\
\hline Patients with OCD & $\begin{array}{l}\text { Patients without OCD } \\
\text { Patients with OCS }\end{array}$ & SAPS & $\begin{array}{l}4.650 \\
5.130\end{array}$ & $\begin{array}{l}1.387 \\
2.203\end{array}$ & $\begin{array}{l}0.003^{*} \\
0.062\end{array}$ & $\begin{array}{c}1.31 \\
-0.017\end{array}$ & $\begin{array}{c}7.99 \\
10.43\end{array}$ \\
\hline Patients with OCS & Patients without OCD & SAPS & -0.480 & 1.905 & 1.000 & -5.07 & 4.11 \\
\hline Patients with OCD & $\begin{array}{l}\text { Patients without OCD } \\
\text { Patients with OCS }\end{array}$ & BPRS & $\begin{array}{l}5.114 \\
5.175\end{array}$ & $\begin{array}{l}1.366 \\
2.170\end{array}$ & $\begin{array}{l}0.001^{*} \\
0.053\end{array}$ & $\begin{array}{c}1.83 \\
-0.05\end{array}$ & $\begin{array}{c}8.40 \\
10.40\end{array}$ \\
\hline Patients with OCS & Patients without OCD & BPRS & -0.061 & 1.876 & 1.000 & -4.58 & 4.46 \\
\hline Patients with OCD & $\begin{array}{l}\text { Patients without OCD } \\
\text { Patients with OCS }\end{array}$ & CGI & $\begin{array}{l}0.405 \\
0.225\end{array}$ & $\begin{array}{l}0.112 \\
0.178\end{array}$ & $\begin{array}{l}0.001^{*} \\
0.624\end{array}$ & $\begin{array}{c}0.14 \\
-0.20\end{array}$ & $\begin{array}{l}0.68 \\
0.65\end{array}$ \\
\hline Patients with OCS & Patients without OCD & CGI & 0.180 & 0.154 & 0.729 & -0.19 & 0.55 \\
\hline Patients with OCD & $\begin{array}{l}\text { Patients without OCD } \\
\text { Patients with OCS }\end{array}$ & GAF & $\begin{array}{l}-5.113 \\
-5.183\end{array}$ & $\begin{array}{l}1.378 \\
2.190\end{array}$ & $\begin{array}{l}0.001^{*} \\
0.056\end{array}$ & $\begin{array}{l}-8.43 \\
-10.46\end{array}$ & $\begin{array}{l}1.78 \\
0.09\end{array}$ \\
\hline Patients with OCS & Patients without OCD & GAF & 0.070 & 1.893 & 1.000 & -4.49 & 4.63 \\
\hline Patients with OCD & $\begin{array}{l}\text { Patients without OCD } \\
\text { Patients with OCS }\end{array}$ & CDSS & $\begin{array}{l}0.740 \\
0.282\end{array}$ & $\begin{array}{l}0.296 \\
0.470\end{array}$ & $\begin{array}{l}0.039^{*} \\
1.000\end{array}$ & $\begin{array}{c}0.03 \\
-0.85\end{array}$ & $\begin{array}{l}1.45 \\
1.41\end{array}$ \\
\hline Patients with OCS & Patients without OCD & CDSS & 0.458 & 0.407 & 0.782 & -0.52 & 1.44 \\
\hline
\end{tabular}


groups, with a mean score of $9.62 \pm 4.37$ in patients with OCD and $6.67 \pm 3.33$ with OCS $(p=0.005$, CI: $0.95-4.96)$. The second most severe dimension in those with OCD was the contamination, whereas symmetry/completeness was more frequent in those with sub-threshold OCS. The YBOCS scores and the OCS dimensions in patients with OCD, and those with sub-threshold OCS are demonstrated in Table 3. There was a significant difference between patients with OCD and OCS in severity of the "unacceptable obsessional thoughts" $(p=0.005)$ and contamination dimensions $(p=0.002)$. However, the severity of responsibility and symmetry/completeness dimensions did not differ between the groups ( $p=0.064, p=0.572$ ). There was no significant difference in respect of the severity of contamination, responsibility, and symmetry dimensions in those with OCD comorbidity. On the other hand, in those with sub-threshold OCS, severity of the symmetry/completeness dimension was higher than the contamination and responsibility dimensions (mean scores of the dimensions: symmetry/ completeness: $2.21 \pm 3.27$, contamination: $0.33 \pm 1.63$, responsibility: $1.34 \pm 2.15$ ).

Table 4 displays the correlation of the DOCS subscales with each other, and other clinical characteristics in patients with OCD comorbidity. No statistically significant difference was determined between the total YBOCS score and 4 DOCS dimensions. There was a positive correlation between contamination and symmetry/completeness dimensions in those with OCD $(p=0.003, r=0.406)$; however, there was no significant association between the other dimensions $(p>0.05)$. In addition, the contamination and symmetry/ completeness dimensions were not associated with any other clinical variables $(p>0.05)$. The YBOCSobsession score was associated with the responsibility score ( $p=0.025, \mathrm{r}=0.318)$, and the YBOCS-compulsion score was correlated with the "unacceptable obsessional thoughts" score $(p=0.021, \mathrm{r}=0.325)$. The severity of "unacceptable obsessional thoughts" dimension showed a positive correlation with the CDSS score $(p=0.028$, $\mathrm{r}=0.311)$, and a negative correlation with the onset age of OCD, and the SAI score $(p=0.050, r=-0.288$; $p=0.040 \mathrm{r}=-0.292)$. The severity of responsibility dimension showed a positive correlation with the SANS score $(p=0.022, \mathrm{r}=0.323)$, and a negative relationship with the GAF score $(p=0.003, \mathrm{r}=-0.408)$.

Discussion. The primary aim of this study was to assess obsessive-compulsive symptom dimensions and to inquire the relationship between the OCS dimensions and the clinical features in patients with schizophrenia. A total of 50 patients (17\%) met the inclusion criteria for OCD comorbidity, and 24 individuals (10\%) showed sub-threshold OCS. Similar to the findings of previous studies, there was a high OCS/OCD prevalence in patients with schizophrenia. ${ }^{6,7}$ Patients with sub-threshold OCS were included as a different group in assessment of OCS dimensions to hinder clinical bias. Age, gender, marital status, and education level did not show a significant difference between the 3 groups, which was consistent with most of the previous studies. ${ }^{3,4}$ On the other hand, some studies reported a significant relationship between the sociodemographic variables and OCD presence in schizophrenia. ${ }^{11}$

There was no significant difference between 3 groups in terms of the duration of schizophrenia. However, all other clinical features showed a significant difference between the 3 groups. Onset of the disorder was younger in the patients with OCS, and OCD comparing with those without OCD. That finding of earlier onset of schizophrenia in the presence of OCD

Table 3 - The YBOCS scores and OCS dimensions in the patients with OCD and those with sub-threshold OCS.

\begin{tabular}{lccccc}
\hline Scores & $\begin{array}{c}\text { Patients with } \\
\text { OCD } \\
(\mathbf{n}=50)\end{array}$ & $\begin{array}{c}\text { Patients with } \\
\text { sub-threshold OCS } \\
(\mathbf{n}=\mathbf{2 4})\end{array}$ & $\begin{array}{c}P \text {-value } \\
\text { to } / \mathbf{z} \text { score }\end{array}$ & $\begin{array}{c}\text { CI (95\%)/ } \\
\text { U value }\end{array}$ \\
\hline YBOCS total score $^{\mathrm{a}}$ & $20.60 \pm 4.07$ & $10.58 \pm 2.06$ & $<0.001^{*}$ & $\mathrm{t}=11.360$ & $8.26-11.77$ \\
YBOCS-obsession score $^{\mathrm{a}}$ & $9.42 \pm 3.04$ & $5.58 \pm 2.02$ & $<0.001^{*}$ & $\mathrm{t}=5.600$ & $2.47-5.20$ \\
YBOCS-compulsion score $^{\mathrm{a}}$ & $11.14 \pm 2.79$ & $5.00 \pm 2.50$ & $<0.001^{*}$ & $\mathrm{t}=9.148$ & $4.80-7.48$ \\
DOCS-contamination score $^{\mathrm{b}}$ & $3.20 \pm 4.35$ & $0.33 \pm 1.63$ & $0.002^{*}$ & $\mathrm{z}=-3.166$ & $\mathrm{U}=382.5$ \\
DOCS-responsibility score $^{\mathrm{a}}$ & $2.80 \pm 4.04$ & $1.34 \pm 2.15$ & 0.064 & $\mathrm{t}=1.759$ & $0.06-3.78$ \\
DOCS-unacceptable obsessional thoughts score $^{\mathrm{a}}$ & $9.62 \pm 4.37$ & $6.67 \pm 3.33$ & $0.005^{*}$ & $\mathrm{t}=2.931$ & $0.95-4.96$ \\
DOCS-symmetry/completeness score $^{\mathrm{a}}$ & $2.72 \pm 3.79$ & $2.21 \pm 3.27$ & 0.572 & $\mathrm{t}=0.568$ & $-1.29-2.31$ \\
\hline
\end{tabular}

Data are mean \pm standard deviation. ${ }^{\mathrm{a} I n d e p e n d e n t ~ s a m p l e ~ t-t e s t, ~}{ }^{\mathrm{b}} \mathrm{Mann}$ Whitney $\mathrm{U}$ test, ${ }^{*} p<0.05, \mathrm{t}$ value: Independent sample t-test,

CI: confidence interval, z and U values: Mann Whitney, OCD: obsessive-compulsive disorder, OCS: obsessive-compulsive symptoms, YBOCS: yale-brown obsessive compulsive scale, DOCS: dimensional obsessive-compulsive scale 
Table 4 - Correlation of the DOCS subscales with clinical characteristics in the patients with OCD comorbidity DOCS subscales.

\begin{tabular}{lcccc}
\hline Variables & $\begin{array}{c}\text { Contamination } \\
(\boldsymbol{P} \text {-value, } \mathbf{r})\end{array}$ & $\begin{array}{c}\text { Responsibility } \\
(\boldsymbol{P} \text {-value, } \mathbf{r})\end{array}$ & $\begin{array}{c}\text { Unacceptable } \\
\text { obsessional thoughts } \\
(\boldsymbol{P} \text {-value, } \mathbf{r})\end{array}$ & $\begin{array}{c}\text { Symmetry/ } \\
\text { completeness } \\
(\boldsymbol{P} \text {-value, } \mathbf{r})\end{array}$ \\
\hline Contamination & $0.642(-0.067)$ & $0.642(-0.067)$ & $0.262(-0.067)$ & $0.003(0.406)$ \\
Responsibility & $0.262(-0.162)$ & $0.310(0.147)$ & $0.310(0.147)$ & $0.640(-0.068)$ \\
Unacceptable obsessional thoughts & $0.003(0.406)$ & $0.640(-0.068)$ & $0.724(-0.051)$ & $0.724(-0.051)$ \\
Symmetry/completeness & $0.468(0.105)$ & $0.083(0.248)$ & $0.021(0.325)$ & $0.241(0.169)$ \\
YBOCS total score & $0.282(0.155)$ & $0.025(0.318)$ & $0.407(0.120)$ & $0.962(0.007)$ \\
YBOCS-Obsession score & $0.969(-0.006)$ & $0.934(-0.012)$ & $0.021(0.325)$ & $0.109(0.230)$ \\
YBOCS-Compulsion score & $0.925(-0.014)$ & $0.910(0.017)$ & $0.031(-0.311)$ & $0.592(-0.079)$ \\
Onset age of OCD & $0.446(-0.110)$ & $0.005(0.392)$ & $0.341(0.138)$ & $0.532(-0.091)$ \\
Duration of OCD & $0.192(0.188)$ & $0.818(0.033)$ & $0.052(-0.288)$ & $0.455(0.108)$ \\
Onset age of schizophrenia & $0.058(-0.269)$ & $0.212(0.180)$ & $0.794(-0.038)$ & $0.111(-0.228)$ \\
Duration of schizophrenia & $0.216(0.178)$ & $0.824(0.032)$ & $0.383(0.126)$ & $0.682(-0.059)$ \\
Duration of clozapine & $0.716(0.053)$ & $0.022(0.323)$ & $0.530(0,091)$ & $0.311(-0.146)$ \\
SANS & $0.700(-0.056)$ & $0.301(0.149)$ & $0.995(-0.001)$ & $0.836(-0.030)$ \\
SAPS & $0.313(-0.146)$ & $0.183(0.191)$ & $0.258(0.163)$ & $0.490(-0.100)$ \\
BPRS & $0.983(-0.003)$ & $0.486(0.101)$ & $0.028(0.311)$ & $0.935(-0.012)$ \\
CDSS & $0.897(-0.019)$ & $0.003(-0.408)$ & $0.278(0.156)$ & $0.850(-0.028)$ \\
GAF & $0.247(0.167)$ & $0.077(-0.252)$ & $0.040(-0.292)$ & $0.186(0.190)$ \\
SAI & & & & \\
\hline
\end{tabular}

YBOCS: yale-brown obsessive compulsive scale, DOCS: dimensional obsessive-compulsive scale, OCD: obsessive-compulsive disorder, SAPS/SANS: Scale for the Assessment of Positive and Negative Symptoms, BPRS: brief psychiatric rating scale, CGI: Clinical Global Impressions Scale, GAF: Global Assessment of Functioning Scale, CDSS: Calgary Depression Scale for Schizophrenia, SAI: schedule for assessing the 3 components of insight, r: Pearson correlation coefficient

comorbidity was consistent with previous studies. ${ }^{5,6}$ The patients with OCD showed higher SANS, SAPS, CGI, BPRS, CDSS, and lower GAF scores compared to the patients without OCD. That outcome demonstrated a significant association between the OCD comorbidity and the severity of clinical features in patients with schizophrenia, as has been reported in previous studies. ${ }^{12-15}$

Although the difference in the severity of clinical characteristics between the patients with OCS, and OCD was not statistically significant, those with OCD comorbidity had higher clinical scores. In addition, there was a significant relationship between the severity of obsessive-compulsive symptoms and psychotic features in the patients with OCD comorbidity, nevertheless, a similar relationship was not determined in those with OCS, and without OCD. Those findings indicated a discrepancy between the patients with OCS, and OCD regarding to the relationship with schizophrenia characteristics. ${ }^{16,19}$ The CGI, SANS, and CDSS scores did not differ between the patients with sub-threshold OCS, and those with OCD. That finding showed that there was no significant difference in the severity of negative and depressive symptoms between the patients with OCD, and OCS. Furthermore, the SAPS, BPRS, and GAF scores were nearly the same in the patients without OCD, and those with sub-threshold OCS. Thus, it can be suggested that there was a strong similarity between those with sub-threshold OCS, and without OCD. ${ }^{21}$

The mean score of unacceptable obsessional thoughts was $9.62 \pm 4.37$ and $6.67 \pm 3.33$ in the patients with OCD and OCS, respectively. Additionally, that dimension was the most severe OCS dimension in the patients with OCD, and OCS. The second most severe dimension in those with OCD was the contamination while the symmetry/completeness dimension was more common in those with sub-threshold OCS. Therefore, OCS dimensions of the patients with OCD and OCS demonstrated a noteworthy difference. There are few studies which used a method of integrating obsessions and compulsions in the assessment of OCS dimensions in schizophrenia. Thus, the studies evaluating the kind of obsession and compulsions in schizophrenia were inquired. However, those studies were also few, relatively older, and obtained inconsistent results. ${ }^{22,23}$ For example, Seedat et $\mathrm{al}^{19}$ found that aggressive obsessions were the most prevalent OCS in patients with schizophrenia while Grover et $\mathrm{a}^{22}$ reported a rare prevalence of aggressive obsessions in schizophrenia. 
Some studies declared a high rate of repetitive behaviors, whereas others reported a high frequency of checking and arranging compulsions. ${ }^{22,23}$ As distinct from most of previous studies, the most severe OCS dimension was the "unacceptable obsessional thoughts" in both the patients with OCD, and OCS. ${ }^{21-23}$ The contamination and symmetry dimensions were less severe in the present study compared to the past studies which have reported a high severity of contamination and symmetry obsessions in schizophrenia and OCD comorbidity. ${ }^{19,22}$

No significant correlation was determined between the total YBOCS score and 4 DOCS dimensions in the present study. It can be suggested that the YBOCS does not reflect the clinical expression of the DOCS dimensions. In addition, there was no significant association between the OCS dimensions, except positive correlation between the contamination and symmetry/completeness dimensions. That finding demonstrated a variety in clinical manifestation of the OCS dimensions in patients with schizophrenia. ${ }^{23}$ In addition, the contamination and symmetry/ completeness dimensions were not associated with any other clinical variables; however, there was a moderate correlation between those dimensions. That result can be interpreted as those dimensions demonstrated a significant relationship with each other, nevertheless, they did not have an impact on the clinical features of schizophrenia.

The severity of "unacceptable obsessional thoughts" was positively correlated with the YBOCS-compulsion and CDSS scores, but negatively correlated with the onset age of OCD and SAI score. Those findings indicated that "unacceptable obsessional thoughts" might have an impact on affective symptoms and insight level in schizophrenia. Therefore, a different clinical relationship can be suggested between the "unacceptable obsessional thoughts" dimension and clinical features of schizophrenia. The severity of the responsibility dimension demonstrated a moderate negative correlation with the functionality score, but a milder positive correlation with the YBOCSobsession score and the severity of negative symptoms. Considering the low severity of responsibility dimension in the present study, the correlations of that dimension should be repeated to prove a real association. In addition, there is a lack of consensus on the association of OCS and psychotic features in the current literature. Therefore, there is a clear need to investigate the OCS dimensions in schizophrenia, and understanding clinical relationships of the dimensions might provide a noteworthy contribution to the issue of OCS/OCD comorbidity in schizophrenia. ${ }^{21}$

Study limitations. It was a cross-sectional study and clinical relationships were not confirmed in a follow-up process. The patients included in the study had a wide variety of clinical characteristics as a general shortcoming of the studies in schizophrenia. However, clinical features of the patients were assessed in detail through valid and reliable scales in the present study, and that was the strength of the study. In addition, that study was the first study using the DOCS in evaluation of the OCS dimensions in schizophrenia.

To summarize, the OCD prevalence in the patients with schizophrenia was high, and almost one-fourth of the patients had OCS or OCD comorbidity in the present study. The OCD comorbidity was related with lower onset age, more severe clinical symptoms, and lower functionality level. Also, the patients with subthreshold OCS manifested a different clinical profile compared to the patients with and without OCD comorbidity. Therefore, patients with schizophrenia should be evaluated for presence of OCS/OCD in clinical practice. There was a variety in clinical manifestation of OCS dimensions, and also a diversity in clinical associations of the dimensions in the present study. Taken together, OCS dimensions might be considered in assessment of the schizophrenia and OCS/OCD comorbidity. Furthermore, dimensional assessment of the OCS might provide a different viewpoint on the presence of OCS/OCD in schizophrenia. Finally, prospective clinical studies with larger samples of patients can clarify the interrelationship between OCS/ OCD and schizophrenia.

Acknowledgment. We would like to thank Editage for English language editing.

\section{References}

1. Galling B, Roldán A, Hagi K, Rietschel L, Walyzada F, Zheng W, et al. Antipsychotic augmentation vs. monotherapy in schizophrenia: systematic review, meta-analysis and metaregression analysis. World Psychiatry 2017; 16: 77-89.

2. Wimberley T, Støvring H, Sørensen HJ, Horsdal HT, MacCabe, $\mathrm{JH}$, Gasse C. Predictors of treatment resistance in patients with schizophrenia: a population based cohort study. Lancet Psychiatry 2016; 3: 358-366.

3. Fernandez-Egea E, Worbe Y, Bernardo M, Robbins TW. Distinct risk factors for obsessive and compulsive symptoms in chronic schizophrenia. Psychol Med 2018; 19: 1-8.

4. Zhou T, Baytunca B, Yu X, Ongür D. Schizo-obsessive disorder: the epidemiology, diagnosis, and treatment of comorbid schizophrenia and OCD. Curr Treat Options Psychiatry 2016; 3: $235-245$. 
5. Devi S, Rao NP, Badamath S, Chandrashekhar C, Reddy YC. Prevalence and clinical correlates of obsessive-compulsive disorder in schizophrenia. Compr Psychiatry 2015; 56: 141-148.

6. Scotti-Muzzi E, Saide OL. Schizo-obsessive spectrum disorders: an update. CNS Spectr 2017; 22: 258-272.

7. Swets M, Dekker J, van Emmerik-van Oortmerssen K, Smid GE, Smit F, de Haan L, et al. The obsessive compulsive spectrum in schizophrenia, a meta-analysis and meta-regression exploring prevalence rates. Schizophr Res 2014; 152: 458-468.

8. Cheng YF, Chen VC, Yang YH, Chen KJ, Lee YC, Lu ML. Risk of schizophrenia among people with obsessive-compulsive disorder: A nationwide population-based cohort study. Schizophr Res 2019; 209: 58-63.

9. Rasmussen AR, Nordgaard J, Parnas J. Schizophrenia-spectrum psychopathology in obsessive-compulsive disorder: an empirical study. Eur Arch Psychiatry Clin Neurosci 2019 [Epub ahead of print].

10. Tonna M, Ottoni R, Paglia F, Monici A, Ossola P, DE Panfilis C. Obsessive-Compulsive Symptoms in Schizophrenia and in Obsessive-Compulsive Disorder: Differences and Similarities. J Psychiatr Pract 2016; 22: 111-116.

11. Cunill R, Castells X, Simeon D. Relationships between obsessive-compulsive symptomatology and severity of psychosis in schizophrenia: a systematic review and meta-analysis. J Clin Psychiatry 2009; 70: 70-82.

12. Fineberg NA, Apergis-Schoute AM, Vaghi MM, Banca P, Gillan CM, Voon V, et al. Mapping Compulsivity in the DSM-5 Obsessive Compulsive and Related Disorders: Cognitive Domains, Neural Circuitry, and Treatment. Int J Neuropsychopharmacol 2018; 21: 42-58.

13. Kim SW, Jeong BO, Kim JM, Shin IS, Hwang MY, Paul Amminger G, et al. Associations of obsessive-compulsive symptoms with clinical and neurocognitive features in schizophrenia according to stage of illness. Psychiatry Res 2015; 226: 368-375.

14. Schirmbeck F, Swets M, Meijer CJ, Zink M, de Haan L, GROUP investigators. Obsessive-compulsive symptoms and overall psychopathology in psychotic disorders: longitudinal assessment of patients and siblings. Eur Arch Psychiatry Clin Neurosci 2018; 268: 279-289.

15. Seng NB, Yee A, Danaee M, Seng LH, Jambunathan ST. The effect of obsessive compulsive symptoms on psychopathology in patients with schizophrenia. Arch Clin Psychiatry 2018; 45: 61-66.

16. Tonna M, Ottoni R, Affaticati A, Ferrari L, Monici A, Ossola P. The impact of obsessive dimension on symptoms and functioning in schizophrenia. Psychiatry Res 2015; 230: 581-584.

17. Frías A, Palma C, Farriols N, Becerra C, Álvarez A, Cañete J. Neuropsychological profile and treatment-related features among patients with comorbidity between schizophrenia spectrum disorder and obsessive- compulsive disorder: Is there evidence for a "schizo-obsessive" subtype? Psychiatry Res 2014; 220: 846-854.
18. Schirmbeck F, Rausch F, Englisch S, Eifler S, Esslinger C, Meyer-Lindenberg A, et al.. Stable cognitive deficits in schizophrenia patients with comorbid obsessive-compulsive symptoms: a 12-month longitudinal study. Schizophr Bull 2013; 39: 1261-1271.

19. Grover S, Dua D, Chakrabarti S, Avasthi A. Obsessive Compulsive Symptoms/disorder in patients with schizophrenia: Prevalence, relationship with other symptom dimensions and impact on functioning. Psychiatry Res 2017; 250: 277-284.

20. Biria M, Huang FX, Worbe Y, Fineberg NA, Robbins TW, Fernandez-Egea E. A cross sectional study of impact and clinical risk factors of antipsychotic-induced OCD. Eur Neuropsychopharmacol 2019; 29(8): 905-913. doi:10.1016/j. euroneuro.2019.06.006.

21. Tezenas du Montcel C, Pelissolo A, Schürhoff F, Pignon B. Obsessive-Compulsive Symptoms in Schizophrenia: an Up-To-Date Review of Literature. Curr Psychiatry Rep 2019; 21: 64.

22. Seedat F, Roos JL, Pretorius HW, Karayiorgou M, Nel B. Prevalence and clinical characteristics of obsessive-compulsive disorder and obsessive compulsive symptoms in Afrikaner schizophrenia and schizoaffective disorder patients. Afr $J$ Psychiatry 2007; 10: 219-224.

23. De Haan L, Sterk B, Wouters L, Linszen DH. The 5-year course of obsessive-compulsive symptoms and obsessive-compulsive disorder in first-episode schizophrenia and related disorders. Schizophr Bull 2013; 39: 151-160.

24. Goodman WK, Price LH, Rasmussen SA, Mazure C, Fleischmann RL, Hill CL. The Yale-Brown Obsessive Compulsive Scale. Development, Use, and Reliability. Arch Gen Psychiatry 1989; 46: 1006-1011.

25. Bener A, Dafeeah EE, Abou-Saleh MT, Bhugra D, Ventriglio A. Schizophrenia and co-morbid obsessive-compulsive disorder: Clinical characteristics. Asian J Psychiatr 2018; 37: 80-84.

26. American Psychiatric Association. Diagnostic and Statistical Manual of Mental Disorders. 5th ed. Washington (DC): American Psychiatric Association; 2013.

27. Overall JE, Gorham DR. The brief psychiatric rating scale (BPRS): recent developments in ascertainment and scaling. Psychopharmacol Bull 1988; 24: 97-99.

28. Guy W. ECDEU Assessment Manual for Psychopharmacology. Rockville (MD): US Department of Heath, Education, and Welfare Public Health Service Alcohol, Drug Abuse, and Mental Health Administration; 1976.

29. Andreasen NC. Methods for assessing positive and negative symptoms. Mod Probl Pharmacopsychiatry 1990; 24: 73-88.

30. Addington D, Addington J, Schissel B. A depression rating scale for schizophrenics. Schizophr Res 1990; 3: 247-251.

31. Abramowitz JS, Deacon BJ, Olatunji BO, Wheaton MG, Berman NC, Losardo D, et al. Assessment of obsessivecompulsive symptom dimensions: Development and evaluation of the dimensional obsessive-compulsive scale. Psychol Assess 2010; 22: 180-198.

32. Endicott J, Spitzer RL, Fleiss JL, Cohen J. The Global Assessment Scale: A Procedure for Measuring Overall Severity of Psychiatric Disturbance. Arch Gen Psychiatry 1976; 33: 766-771. 